\title{
Differential nest-defense to perceived danger in urban and rural areas by female Eurasian sparrowhawk (Accipiter nisus)
}

Tomas Kunca, Reuven Yosef

The reaction of wildlife to humans is known to differ with surroundings. In urban environments that provide suitable habitats for breeding birds, animals adapt to humans and their response is accordingly altered. This study examined the nest defense behavior of female Eurasian sparrowhawks (Accipiter nisus) during the breeding season in urban and rural areas of Prague. The females showed four different types of reaction to humans that approached the nest and differed significantly between the two study areas. Contrary to the expected, urban nesting females were more aggressive than rural conspecifics. Intensity of response intensified as the season progressed and females defended their broods to a much greater degree than their clutches in both urban and rural habitats suggesting a differential effort as a function of their relative investment in the breeding attempt conforming with the parental investment hypothesis. 
1 Differential nest-defense to perceived danger in urban and rural areas by

2 female Eurasian sparrowhawk (Accipiter nisus)

3

4 Tomáš Kunca ${ }^{1}$, Reuven Yosef $^{2}$

$5 \quad{ }^{1}$ Faculty of Environmental Sciences, Czech University of Life Sciences Prague, Czech Republic

$6 \quad{ }^{2}$ Ben Gurion University of the Negev - Eilat Campus, Eilat, Israel

7

8 Corresponding author:

9 Tomáš Kunca

10 V Parku 832, Nový Bor, 473 01, Czech Republic

11 Email address: tkunca@gmail.com

12

13 


\section{Abstract}

15 The reaction of wildlife to humans is known to differ according to their surroundings. In urban

16 environments that provide habitats for breeding birds, animals adapt to humans and their

17 response alters accordingly. This study examined the nest defense behavior of female Eurasian

18 sparrowhawks (Accipiter nisus) during the breeding season in urban and rural areas of Prague.

19 The females showed four different types of reactions to humans that approached the nest, which

20 differed significantly between the two study areas. Contrary to the expected, urban nesting

21 females were more aggressive than rural conspecifics. Intensity of response intensified as the

22 season progressed and females defended their broods to a much greater degree than their clutches

23 in both urban and rural habitats, suggesting a differential effort as a function of their relative

24 investment in the breeding attempt, conforming with the parental investment hypothesis. 
27

\section{Introduction}

Wildlife are known react to perceived danger, including human presence, which affects their normal behavior and responses in a wide range of species-specific ways (Dukas, 2001;

Wojciechowski \& Yosef, 2011). The animals reaction to perceived danger is known to influence its fitness and life history, and to affect other behaviors such as inter- and intra-specific interactions and foraging considerations (e.g., Grubb \& Greenwald, 1982; Morse, 1986; Nonacs \& Dill, 1990; Watts, 1990; Stamps \& Bowers, 1991; Martin, 1995; Slotow, 1996). Whittaker \& Knight (1998) considered the reaction of an individual as the combination of learning and genetics.

$$
\text { Expanding human populations in almost every habitat on the globe has resulted in wildlife }
$$
having to contend with greater disturbances in their natural environments or outright destruction of existing habitats. The outcome of ever-increasing human-animal encounters influences the learning components of animals (Knight \& Temple, 1986). With the growing human population natural environments have become increasingly modified by humans and some species have reacted to such changes by habituation. Urban areas, in the form of cities, provide habitats for many animal species that willingly overcome ecological barriers of urbanization and adapt to the human-dictated conditions (Luniak, 2004). Interest in urbanization of birds is not novel (Erz, 1966) and the number of studies that describe avian responses to urbanization is immense and growing (Marzluff, Bowman \& Donelly, 2001). In particular, some raptor species find urban habitats very suitable as they provide large amounts of food in the form of human commensals (e.g., Feral Pigeons, Columba livia; Sparrows, Passer spp.; Brown Rats, Rattus norvegicus), quality nesting places and are free from some ecological pressures, such as persecution (Chace \& Walsh, 2006). However, in the presence of persecution, or high levels of disturbance resulting in 
50 stress or unsuccessful breeding, it would be maladaptive to habituate to human predominant

51 environments and birds can be expected to display avoidance behavior or increased aggression

52 towards the instigator of the disturbance (Shannon et al., 2014). Persecuted avian species are

53 known to behave differently in rural and urban environments (Kenney \& Knight, 1992). As a

54 result of direct persecution/disturbance and subsequent evasion, breeding birds react to perceived

55 danger with stereotypic antipredator behavior. Nest predation is an important factor limiting

56 breeding success and various birds view humans as potential predators (Fisher et al., 2004).

57 Thus, defending the nest can reduce the parents' wasted energetic investment caused by the loss

58 of a clutch or brood (Grim, 2008). Studies of avian nest defense show an increase in the intensity

59 of the parents' defense as the breeding period progresses, i.e., the more advanced the breeding

60 stage the greater the parents' energetic investment in the reproductive attempt, resulting in an

61 increased effort to defend their young (e.g., Merritt, 1984; Shields, 1984; Sergio \& Bogliani,

62 2001). The afore-mentioned studies conform to the parental investment hypothesis (Trivers,

63 1972; Barash, 1975). However, Knight \& Temple (1986) discovered that nest defense behavior

64 was gradually modified by repeated visits to the nests, consequently resulting in the parents' loss

65 of fear.

66 The Eurasian sparrowhawk (Accipiter nisus) is a common raptor that prefers to breed in

67 woods and forests where it can find an abundance of prey (Newton, 1986). Sparrowhawks started

68 to breed in Prague in the early 1980's (Š́t’astný, Randík \& Hudec, 1987), between 1985-2004 the

69 numbers of breeding pairs varied greatly (42-91 pairs), and eventually stabilized at 45-55

70 breeding pairs. However, because not all the individuals in the urban and surrounding rural areas

71 are ringed for individual identification, we remain ignorant about the origins of the breeding

72 population (sensu latu - the pioneer pairs; Rutz 2008), the turnover within the urban population, 
73 or if the urban population is a source or a sink. At present, ringing of the city-bred young show

74 that they comprise a substantial proportion of the individuals that are recruited into the breeding

75 urban population (Peške in Fuchs et al., 2002). In rural areas, sparrowhawks have been

76 persecuted by gamekeepers for centuries and whilst it was largely stopped in the 1980's,

77 sparrowhawks were still hunted in the Czech Republic in the 1990's (Myslivecká statistika MZe

78 ČR, 2014).

79 In order to understand the influence of human activities on rural and urban sparrowhawk

80 breeding pairs, we compared the reactions of breeding females to perceived danger. We

81 hypothesized that we would find a greater degree of disparity between the behaviors of the urban

82 and rural breeding females. We tested our hypothesis only on females due to the fact that in

83 sparrowhawks in the immediate vicinity of the nest, is the female sparrowhawks usually repel

84 intruders or react to perceived danger (Newton, 1986). Hence, in order to check our hypotheses

85 we observed the nest defense of adult female sparrowhawks during the breeding season in an

86 urban area with high human density where we assumed sparrowhawks to be habituated to human

87 beings, and in a rural area in which sparrowhawks live in the wild and have minimal contact with

88 humans.

89 Material and methods

$90 \quad$ Study area

91 The urban study was conducted in the center of Prague, Czech Republic $\left(\sim 240 \mathrm{~km}^{2}\right.$, radius of

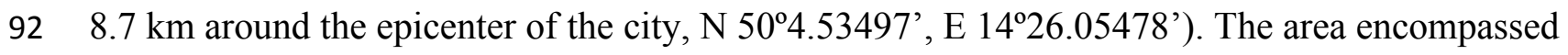

93 by the breeding sparrowhawks, included neighborhoods with residential housing, business

94 districts and industrial areas. Sparrowhawks bred in parks, gardens and cemeteries. The rural 
95 study area was situated in the Liberec region of north Bohemia (N 5049.57548', E

$\left.961^{\circ} 35.28330^{\prime}\right)$ where sparrowhawks are found in large tracks of natural forest. The distance

97 between the two areas is $\sim 100 \mathrm{~km}$. In both study areas data were compiled simultaneously during

98 the breeding season which extended from early May to June 2013. In our analysis we included

99 only those nests which were located during the building stage and prior to egg laying. In

100 addition, two nests that failed to fledge young were not included in our analysis. The nest sites

101 were only visited twice during the breeding cycle in order to avoid habituation of birds to human

102 approach since multiple visits are known to influence the female's reaction (Knight \& Temple,

103 1986). At each of these visits we conducted this experiment and also verified the breeding

104 reproductive stage.

105 Eurasian sparrowhawk is characterized by a strong sexual dimorphism. The females are 106 almost twice the size of the males and their undersides have grayish-brown striations, while 107 those of the male are rusty in color. Another important fact is that the males very rarely incubate 108 the eggs and do so only when the female is feeding, furthermore they never brood the young 109 (Newton, 1986). The higher pitch call of the male also helps distinguish between the two sexes.

110 These differences allowed us to be confident in knowing which bird we were observing during

111 our visits.

112 Data collection

113 We recorded the response of each incubating female twice during the breeding season.

114 Based on our data from previous years and on the different related behavior, we were able to

115 estimate the different stages of the reproductive cycle. The first trial was conducted during the 116 second half of incubation and the second trial during the first week of the nestling stage. We 
117 approached the nest from the nearest path most frequented by humans, in a very obvious manner,

118 and once at the base of the nest tree, recorded the female's reactions for five minutes. To

119 minimize any influence of inclement weather, nest visits were made during windless days with

120 no precipitation. We categorized the female reactions into four behavioral responses. None of the

121 observed females had reactions that spanned multiple behavioral responses:

122 1) skittish: leaves the nest at our approach, remains silent throughout the visit and does not visit

123 the nest the 5 min period during which we stand at the base of the tree;

124 2) alert: alert to our approach but leaves the nest only when we are at the base of the nest tree, 125 utters warning calls, irregularly spotted passing the nest tree during the 5 min period;

126 3) angry: alert to our approach and does not leave the nest while we stand at the base of the nest

127 tree, leaves the nest only after gentle shaking of the nest tree, utters repeated warning calls, 128 remains in eye-contact with the nest from adjacent trees;

129 4) intense: alert to our approach, does not leave the nest while we stand at base of the nest tree, 130 refuses to leave the nest even when the tree is shaken, responds by aggressive wing beating 131 against nest edge, aggressive posturing/mantling on the nest.

132 We used a Nikon Forestry PRO (Nikon Vision, Tokyo, Japan) to measure nest height and 133 distance to the path. We categorized the habitat, where the nest was located, into four types 134 according to the number of trees and basal area within a radius of $100 \mathrm{~m}$ around the nest tree:

135 1) Very dense stand comprised of either young spruce (Picea spp.) or pine (Pinus spp.) with $136>15 \mathrm{~cm}$ diameter at breast height $(\mathrm{DBH})$; 
137 2) Dense stand comprised of either one tree species or mixed coniferous (spruce, pine and larch,

138 Larix spp.) with diameter $>30 \mathrm{~cm} \mathrm{DBH}$;

139 3) full-grown mixed forest with diameter $<30 \mathrm{~cm} \mathrm{DBH}$;

140 4) Solitary, fully-grown trees in city parks, and cemeteries.

141 Data analyses

142 Generalized linear models (GLM) with binomial distribution of errors of response variables (i.e.

143 presence or absence of certain type of reaction) were employed to analyse possible effects of

144 explanatory variables (locality - urban/rural; breeding stage - incubation/brooding; habitat;

145 distance to path; individuality) using R (RDCT, 2011). Data on nest height and its distance from

146 the path were logarithmically transformed to approach normality. The nest height (continuous

147 variable) and habitat (categorical variable) were not independent $(\mathrm{F}=34.182, \mathrm{Df}=3, \mathrm{P}<0.001)$

148 and therefore only the habitat was used in the analysis. Although this variable is more complex,

149 it is more relevant to the object of our study. Individuality of the female was factored with a

150 random effect. Individuality was used because each female's response was included in the model

151 twice (incubation/brood). By use of the individuality index we avoided pseudoreplication given

152 that two observations were conducted at each nest. We ran a model for each female's reaction

153 resulting in four separate models. Full models, containing all explanatory variables, were then

154 simplified, i.e. all non-significant explanatory variables $(\mathrm{P}>0.05)$ were excluded step-by-step,

155 using the backward selection procedure (Crawley, 2007). Because of the nature of the statistical

156 analysis, the significance level for the final results was tightened $(\mathrm{P}<0.01)$ to reduce type I

157 error. Before we used the final model we tested its parsimony and compared the null model with

158 the full model. The full model did not improve the significance and the AIC value was low (null 
159 model AIC: 73.811, full model AIC: 62.907, used model AIC: 62.666). By running four different

160 models, we were able to see the separate effect of the factors on each of the female's responses

161 (cf. Slamova, Klecka \& Konvicka, 2010). .

162 Frequency of each reaction type during incubation and brooding was proportionally expressed as

163 a result of presence of the reaction from the total of observations.

\section{Results}

165 Responses of females were observed at 17 rural nest sites and 19 urban nest sites. All four 166 types of nest defense were observed in both rural and urban environments. The most frequent

167 behaviors observed were the extreme reactions, i.e., either the first (skittish) or the fourth

168 (intense) types, whilst the second (alert) type of behavior was relatively scarce (Table 1.).

rural area and $33.6 \mathrm{~m}( \pm 29.95 \mathrm{SD})$ in the urban area. The distance from the path to the nest and

171 the habitat type did not affect the females' response to human approach. The locality played a

172 significant role in the "alert" $\left(\chi^{2}=6.07, \mathrm{Df}=1, \mathrm{P}=0.01\right)$ and the "intense" $\left(\chi^{2}=6.32, \mathrm{Df}=1, \mathrm{P}=\right.$

173 0.01) responses, with "alert" being most commonly observed at rural sites, while the "intense"

174 response was most common at urban nests. Reluctance to leave the nest and aggressive behavior

175 towards the human, classified as "intense", were more frequent at urban sites (84.6\%) than at

176 rural sites (15.4\%). Although not statistically significant, a trend was found in the effect of stage

177 of breeding on the female's behavior in the "skittish" $\left(\chi^{2}=4.80, \mathrm{Df}=1, \mathrm{P}=0.02\right)$ and "intense"

$178\left(\chi^{2}=4.24, \mathrm{Df}=1, \mathrm{P}=0.03\right.$; Table 2.$)$ responses. The first type response; females left the nest

179 more willingly while incubating eggs $(65.0 \%)$ than while brooding young $(35.0 \%)$. The fourth 
180 type response; females refused to leave the nestlings more than when incubating $(57.7 \%$ vs.

$18142.3 \%$ resp.). The third type of behavior was not affected by any of the explanatory variables.

182 We found that the height at which the nest is built is dependent on the density of the vegetation

183 surrounding, the nest tree $(\mathrm{F}=34.182, \mathrm{Df}=3, \mathrm{P}<0.001)$. The sparrowhawks placed their nests

184 lower in trees with denser vegetation (Fig. 1).

\section{Discussion}

Habituation of wildlife to human settlements has been noted since humans first created collective communities. However, the sensitivities and the degree to which each species responds are not yet understood and probably changes on an annual or generational basis. Many domesticated animals, especially dogs (Canis familiaris), are known to follow the human gaze and understand what is required of them, or aim to please their human companion, (Horowitz, 2010). In addition, the study of animal behavior is also known to greatly contribute to conservation of the studied species in the wild (Clemens \& Buchholz, 1997). Hence, we examined nest defense behavior of female sparrowhawks during the incubation and the brooding stages of the reproductive cycle, as a function of distance from the human-frequented trail to the nest and rural/urban habitats. Our hypothesis was repudiated because habituation to humans had a negative influence on the sparrowhawks and their reactions were significantly more aggressive in the urban area. Even though sparrowhawks in Prague are exposed to nonthreatening humans more often than are sparrowhawks in rural areas, and have greater opportunities to learn from their interactions, their responses were more aggressive. Such aggressiveness in urban breeding 200 birds was observed also in other species (Knight, Grout \& Temple, 1987). This does not support 
202 allow the sparrowhawks to habituate to the constant disturbance. On the contrary, we discovered

203 that the females in urban areas appeared to have much higher stress levels than those in the rural

204 areas. In rural areas, breeding sparrowhawks avoided humans in spite of minimal or no prior

205 contact. In Japan, Abe et al., (2007) demonstrated that in spite of the absence of persecution,

206 sparrowhawks chose to nest in relatively undisturbed portions of habitat, in comparison to places

207 of increased human activity.

Humans are known to impact wildlife with almost every activity in which we indulge path to the nest was shorter in Prague where parks are regularly used by humans for recreational purposes. Our findings concur with Smith, Bosakowski \& Devine (1999) who also found a similar pattern in other avian species nesting in both rural and urban environments. The recreational path represents an open space for flying birds and adults often take advantage of assumed that nesting birds in urban areas should be habituated to human presence, the aggressive reaction was greatest in these surroundings. This leads us to consider the point that we assume

217 that urban wildlife undergo a habituation process and hence are able to live in urban areas. In a high disturbance environment habituation to the disturbing stimulus is assumed to be adaptive, and in urban settings this is likely to take the form of noise or humans passing close to the nest.

220 These will be largely harmless, so in this situation, habituation would surely be of benefit to the 221 birds, as they will spend more time at the nest and also draw less attention to the location of the 222 nest site. However, the extreme behaviors displayed by the female sparrowhawks in the defense 223 of their nests actually suggest this widespread assumption to be incorrect and that wildlife, 224 regardless of the amount of human presence, does not really adjust to our activities. In fact, 
225 wildlife remains apprehensive of our presence and the high levels of disturbance appear to result

226 in increased levels of aggression towards those that disturb the nest-tree, irrespective of the

227 "habituation".

228 Our findings suggest that the distance from the path to the nest is not as important for

229 choosing the nest site as the structure of the surrounding woods and the specific tree chosen in

230 which to build the nest. These findings are similar to those of Newton (1986). Furthermore, it

231 appears that although the sparrowhawks have adapted to living in urban areas they have not

232 adapted to human disturbance, nor lost their defensive mechanisms. Our results suggest that the

233 urban breeding pairs are constantly at greater stress levels than conspecifics breeding in rural

234 areas. In consideration of the significant fact that raptors breed in urban environments (e. g.,

235 Bird, Varland \& Negro, 1996, Berry, Bock \& Haire, 1998), it is important to elucidate the

236 physiological differences between the two populations in future studies, by evaluating the

237 different stress levels using diverse techniques such as corticosterone levels (e.g., Bortolotti et al.

238 2008, 2009) or ptilochronology (e.g., Gombobaatar, Yosef \& Odkhuu 2009).

239 One of the main predictors of the female sparrowhawks' response to human approach was

240 the stage of the breeding cycle. In both, the urban and rural sparrowhawks, the females defended

241 their broods more tenaciously than when incubating their eggs. The later the provocation was in

242 the breeding cycle, the more aggressive the reaction of the birds was to humans, and/or the more

243 reluctant the female sparrowhawks were to leave the nest. Similar results were attained in other

244 avian species that were also approached by humans (Andersen, 1990; Sproat \& Ritchison, 1993;

245 Sergio \& Bogliani, 2001) supporting the parental investment theory (Trivers, 1972). 
Two other factors that were not evaluated in our study but could potentially have an impact

247 on a females' behavior are the age and breeding experience of the female and clutch size. If the

248 suggestions of Knight \& Temple (1986) are correct then it is possible that older females, with

249 increasing experience, will react differentially to humans as compared to younger, inexperienced

250 females. Also, in order to further verify the parental investment theory (Trivers, 1972) we

251 consider it probable that females will defend larger clutches more vigorously as compared to

252 smaller ones, despite the study of Osiejuk \& Kuczynski (2007) who found the effect of clutch

253 size on flushing distance was small and did not support the parental investment theory. In

254 general, the sparrowhawk's behavior could also be altered by human persecution. This study

255 does not reveal whether the reduced nest defense in rural sparrowhawks is a change in gene

256 frequency due to persecution of more aggressive and less cautious individuals or whether

257 increased aggressiveness in urban sparrowhawks is learned as a result of the greater frequency of

258 disturbance.

259 Another important point that resulted from this study is the fact that sparrowhawks display

260 the ability to choose the height at which to place their nest as a function of the density of the

261 vegetation surrounding the nest tree (Fig. 1). We assume that this may not really be the case and

262 that sparrowhawks are unable to discern or evaluate vegetation density, but recognize niches that

263 will hinder the approach of a potential predator. We think that because flight is the most

264 expensive behavior (cf. Norberg 1995), especially when carrying extra weight in the form of

265 prey to the nest, it would be advantageous for the breeding pair to nest low and to save the

266 energy invested in flying to the higher parts of the tree. This concurs with Newton (1986) who

267 also found that nest height was dictated by vegetal density and age.

\section{Conclusions}


We found that female sparrowhawks breeding in the urban environment of the city of Prague

270 displayed a greater degree of aggression and agitation than their conspecifics that breed in rural

271 areas. Furthermore, we found that parental investment in the form of nest defense increases with

272 the breeding cycle and that parents with nestlings showed greater levels of defense behavior

273 compared to when they were incubating eggs. In addition, in order to better defend their nests

274 from predators, and yet to enable easier access to them, it appears that in dense vegetation, nests

275 were placed comparatively lower than those in more open vegetation.

\section{Acknowledgements}

277 We thank Miroslav Š́lek and David Horobin for comments on an earlier version of the paper 278 and Sue Har-Shefi for the improvement of the language.

\section{References}

Abe F, Hasegawa O, Kudo T, Higashi S. 2007. Nest-site selection of Northern Goshawks and

Research 41:299-306.

Andersen DE. 1990. Nest defense behavior of red-tailed hawks. Condor 92:991-997.

Barash DP. 1975. Evolutionary aspects of parental behavior: distraction behavior of the Alpine Accentor. Wilson Bulletin 87:367-373. an urbanized landscape. Condor 100:601-608. 
289 Bird DM, Varland DE, Negro JJ. 1996. Raptors in Human Landscapes: Adaptation to

290 Built and Cultivated Environments. London: Raptor Research Foundation and Academic Press.

291 Bortolotti GR, Marchant T, Blas J, German T. 2008. Corticosterone in feathers is a long-term, 292 integrated measure of avian stress physiology. Functional Ecology 22:494-500.

293 Bortolotti GR, Marchant T, Blas J, Cabezas S. 2009. Tracking stress: localisation, deposition and 294 stability of corticosterone in feathers. Journal of Experimental Biology 212:1477-1482.

Bujoczek M, Ciach M, Yosef R. 2011. Road-kills affect avian population quality. Biological 296 Conservation 144:1036-1039.

297 298

Chace JF, Walsh JJ. 2006. Urban effects on native avifauna: a review. Landscape and Urban Planning 74:46-69.

Clemens JR, Buchholz R. 1997. Behavioral approaches to conservation in the wild. Cambridge: Cambridge University Press,

Crawley MJ. 2007. The R Book. Chichester: John Wiley \& Sons Ltd.

Dukas R. 2001. Effects of perceived danger on flower choice by bees. Ecology Letters 4:327333.

Erz W. 1966. Ecological principles in the urbanization of birds. Ostrich 37:357-363.

Fisher RJ, Poulin RG, Todd LD., Brigham RM. 2004. Nest stage, wind speed, and air temperature affect the nest defence behaviours of burrowing owls. Canadian Journal of Zoology 82:707-713. 
308 Fuchs R, Škopek J, Formánek J, Exnerová A. 2002. Atlas Hnízdního Rozšǐrení Ptáki̊ Prahy.

309 Praha: Consult.

310 Glasson J, Godfrey K, Goodey B. 1995. Towards Visitor Impact Management. Avebury:

311 Aldershot.

312 Grim T. 2008. Are Blackcaps (Sylvia atricapilla) defending their nests also calling for help from

313 their neighbours? Journal of Ornithology 149:169-180.

314 Grubb TC, Greenwald L. 1982. Sparrows and a brush pile: foraging responses to different

315 combinations of predation risk and energy costs. Animal Behaviour 30:637-640.

316 Horowitz A. 2010. Inside of a Dog's mind: What Dogs see, smell and know. New York: Scribner.

317 Gombobaatar S, Yosef R, Odkhuu B. 2009. Brandt's Vole density affects reproduction of

318 Upland Buzzards. Ornis Fennica 86:1-9.

319 Kenney SP, Knight RL. 1992. Flight distances of black-billed magpies in different regimes of

320 human density and persecution. Condor 94:545-547.

321 Kenward, R. 2006. The Goshawk. London: Poyser.

322 Knight RL, Temple SA. 1986. Why does avian nest defense increase during the nesting cycle?

323 Auk 103:318-327.

324 Knight RL, Grout DJ, Temple SS. 1987. Nest-defense behavior of the American crow in urban 325 and rural areas. Condor 89:175-177.

326 Knight RL, Gutzweiller KJ. 1995. Wildlife and Recreationists. Washington DC: Island Press. 
327 Luniak M. 2004. Synurbization - adaptation of animal wildlife to urban development. In: Shaw

328 W, Harris LK, Vandruff L, eds. Proc. 4th Int. Symposium Urban Wildlife Conservation (W).

329 Tucson. USA, 50-55.

330 Marzluff JM, Bowman R, Donelly R. 2001. Avian Ecology and Conservation in an Urbanizing

331 World. Boston: Kluwer Academic Publishers.

332 Merritt PG, 1984. Observer recognition by the Northern Mockingbird. Journal of Field

333 Ornithology 55:252- 253.

334 Ministerstvo Zemědělství ČR. 2014. Available at

335 http://eagri.cz/public/web/mze/lesy/statistika/myslivost/x2001-2010/ (accessed 1 May 2014)

336 Morse DH. 1986. Predation risk to insect foraging at flowers. Oikos 46:223-228.

337 Newton I. 1986. The Sparrowhawk. Calton: T \& A. D. Poyser.

338 Newton I. 1979. Population Ecology of Raptors. Berkhamsted: T \& A. D. Poyser.

339 Nonacs P, Dill LM. 1990. Mortality risk vs food quality trade-offs in a common currency: and 340 patch preferences. Ecology 71:1886-1892.

341 Norberg UM. 1995. How a Long Tail and Changes in Mass and Wing Shape Affect the Cost

342 for Flight in Animals. Functional Ecology 9:48-54.

343 Osiejuk TS, Kuczynski L. 2007. Factors affecting flushing distance in incubating female greylag 344 geese Anser anser. Wildlife Biology 13:11-18. 
345 Peške L. 1992. Studium hnízdní populace krahujce obecného (Accipiter nisus) na území Velké

346 Prahy. Zprávy České společnosti ornitologické 34:15-16.

347 R Development Core Team. 2011. R: A language and environment for statistical computing. $R$

348 Foundation for Statistical Computing, Vienna, Austria, ISBN 3-900051-07-0

349 Rein H, Scharpf H. 1997. Biodiversity and Tourism. German Federal Agency for Nature

350 Conservation, Berlin Heidelburg: Springrer-Verlag

351 Rutz C. 2008. The establishment of an urban bird population. Journal of Animal Ecology

$35277: 1008-1019$.

353 Sergio F, Bogliani G. 2001. Nest defense as parental care in the Northern Hobby (Falco

354 subbuteo). Auk 118:1047-1052.

355 Shannon G, Angeloni LM, Wittemyer G, Fristup KM, Crooks KR. 2014. Road traffic noise 356 modifies behavior of a keystone species. Animal Behaviour 94:135-141.

357 Shields WM. 1984. Barn swallow mobbing: self-defence, collateral kin defence, group defence, 358 or parental care? Animal Behaviour 32:132-148.

359 Slamova I, Klecka J, Konvicka M. 2011. Diurnal behavior and habitat preferences of Erebia 360 aethiops, an aberrant lowland species of a mountain butterfly clade. Journal of Insect Behaviour $361 \quad 24: 230-246$.

362 Slotow R. 1996. Aggression in white-crowned sparrows: effects of distance from cover and 363 group size. Condor 98:245-252. 
364 Smith DG, Bosakowski T, Devine A. 1999. Nest site selection by urban and rural great horned 365 owls in the northeast. Journal of Field Ornithology 70:535-542.

366 Sproat TM, Ritchinson G. 1993. The nest defense behavior of Eastern Screech- Owls: effects of 367 nest stage, sex, nest type and predator location. Condor 95:288-296.

368 Stamps NE, Bowers MD. 1991. Indirect effect on survivorship of caterpillars due to presence of 369 invertebrate predator. Oecologica 88:325-330.

370 Trivers RL. 1972. Parental investment and sexual selection In: Campbell B, ed. Sexual selection 371 and the descent of man. Chicago: Al-dine, 135-179.

372 Št’astný K, Randík A, Hudec K. 1987. Atlas hnizdního rozšíření ptáků v ČSSR1973/77. Praha: 373 Academia.

374 Watts BD. 1990. Cover use and predator-related mortality in song and savanna sparrows. Auk $375 \quad 107: 775-778$.

376 Whittaker D, Knight RL. 1998. Understanding wildlife responses to humans. Wildlife Society 377 Bulletin 26:312-317.

378 Wojciechowski M, Yosef R. 2011. House martin (Delichon urbica) response to perceived 379 danger. Journal of Ethology 29:93-94. 
Figure 1.

381 The relation of nest height (log transformed) on vegetal density in close vicinity of the nest tree -

382 habitat type 1 is dense and that impedes access, habitat 2 and 3 are intermediate in density to 1

383 and 4 and habitat type 4 is sparse, Czech Republic, 2013.

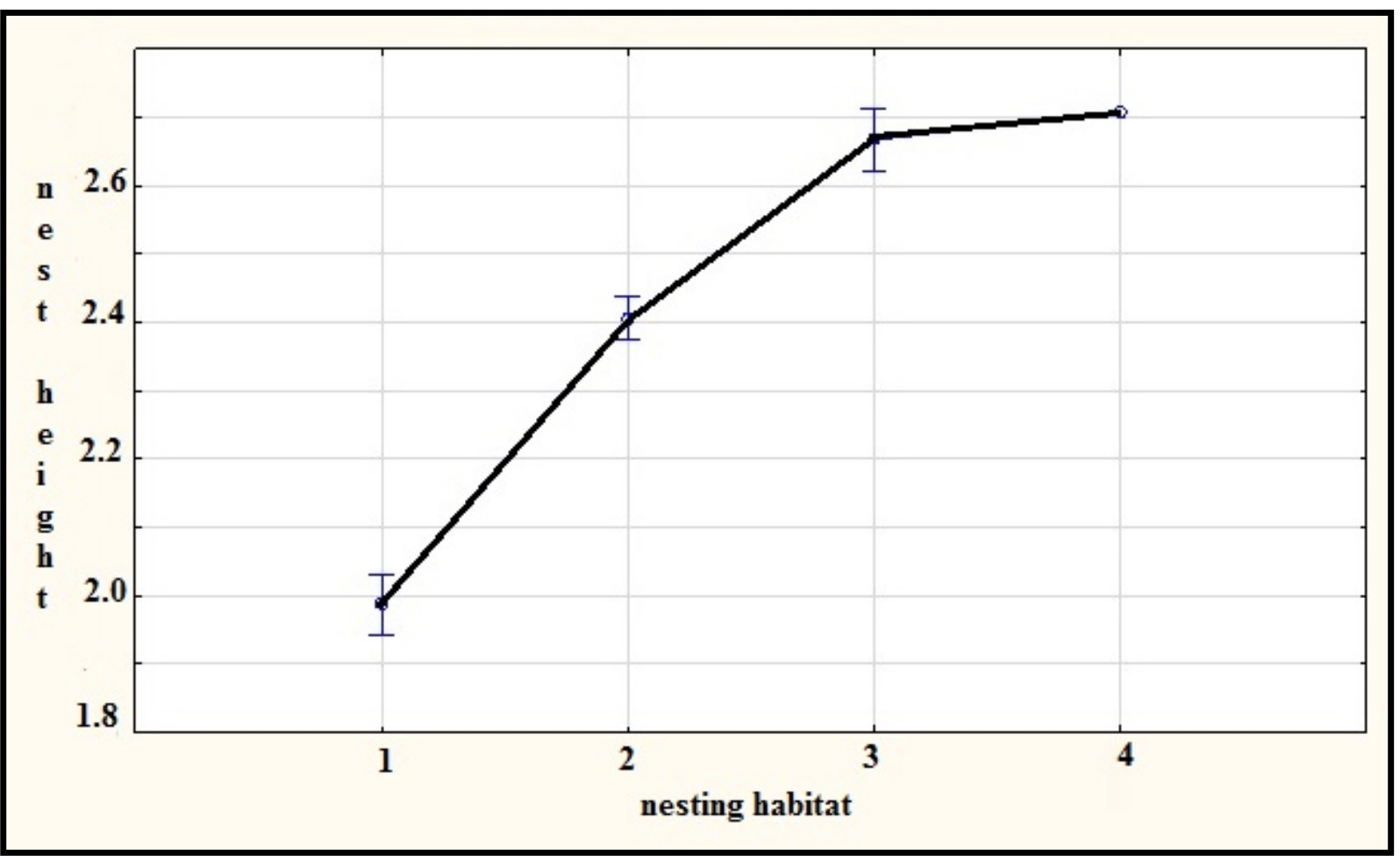


386 Table 1.

387 Comparative response occurrence of females Eurasian sparrowhawk (Accipiter nisus) when 388 incubating eggs and brooding nestling in the Czech Republic in 2013.

\begin{tabular}{llllllllll}
\hline Incubation & \multicolumn{10}{c}{ Brooding } \\
\hline Locality/response & Skittish & Alert & Angry & Intense & & Skittish & Alert & Angry & Intense \\
Urban & $27 \%$ & $0 \%$ & $21 \%$ & $53 \%$ & Urban & $21 \%$ & $0 \%$ & $16 \%$ & $63 \%$ \\
Rural & $47 \%$ & $18 \%$ & $29 \%$ & $6 \%$ & Rural & $18 \%$ & $35 \%$ & $29 \%$ & $18 \%$ \\
\hline
\end{tabular}


390 Table 2.

391 Data analyses of the responses of females Eurasian sparrowhawk (Accipiter nisus) to the human 392 approach in the Czech Republic in 2013 - effect of variables on the female's response (response 3931 - skittish, response 2 - alert, response 3 - angry, response 4 - intense).

394

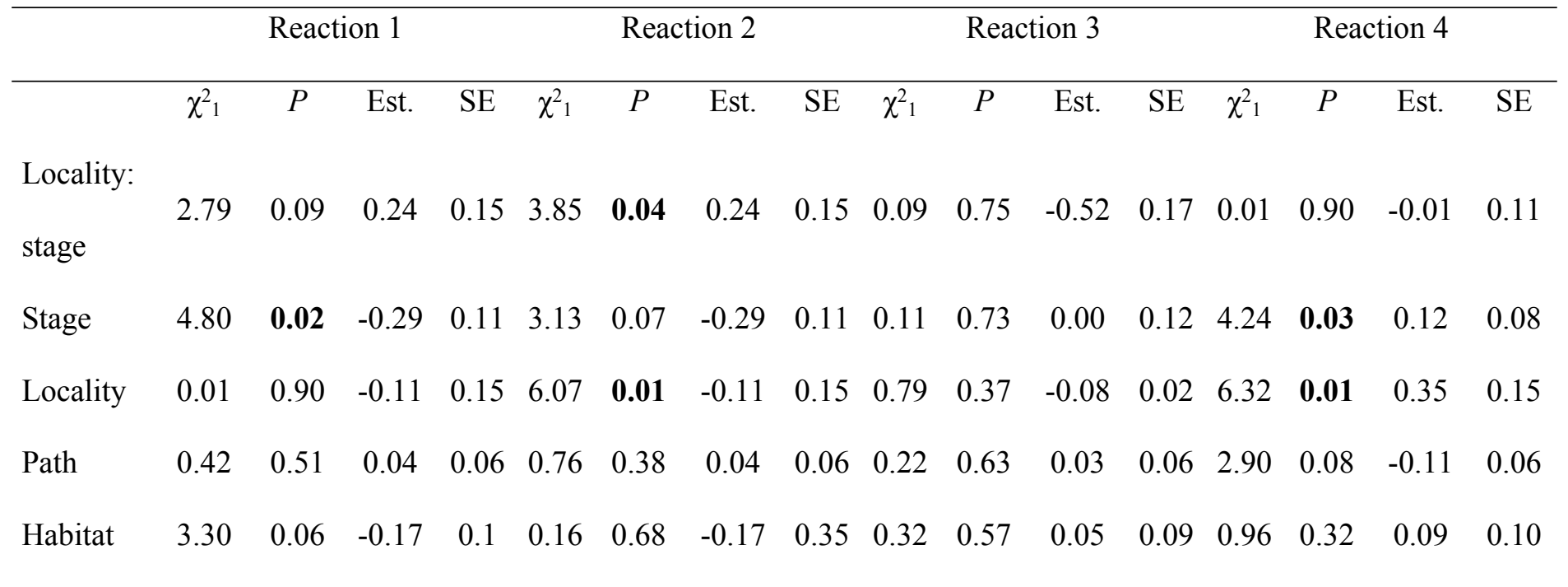
395 